\title{
ANÁLISE SOBRE A PRODUÇ̃̃̃O ASSISTENCIAL NA SAÚDE SUPLEMENTAR DO BRASIL ENTRE OS ANOS DE 2011E 2017
}

\begin{abstract}
> INTRODUÇÃO
Um a cada quatro brasileiros possuía plano ou seguro de assistência mèdico-hospitalar em 2017, indicando que o sistema de Saúde Suplementar (SS) é um importante pilar para manter a sustentabilidade do setor de saúde. Dada elevadar revancla desse setor epensando em controur alnda más com a discom objetivo de observar a evolução dos procedimentos e despesas assistenciais realizadas pelos planos de saúde de assistência médico-hospitalar entre os anos de 2011 e 2017 .
\end{abstract}

$>$ MÉTODOS

Os dados foram coletados do Mapa Assistencial da Saúde Suplementar publicado desde 2012 pela Agêncía Nacionte de informaçôes é o Sistema de Informações de Produtos (SIP) uma base de dados da ANS que coleta periodicamente as informaçôes assistenciais das operadoras de planos privados.

$>$ RESULTADOS

De acordo com a publicação, o setor de saúde suplementar contabilizou cerca avanço de $3,2 \%$ em relação aos resultados do ano de 2016 (tabela 1)

Tabela 1. Evolução do número de procedimentos de assistência médico-hospitalar prestados no sistema de saúde suplementar entre 2011 a 2017 e va-

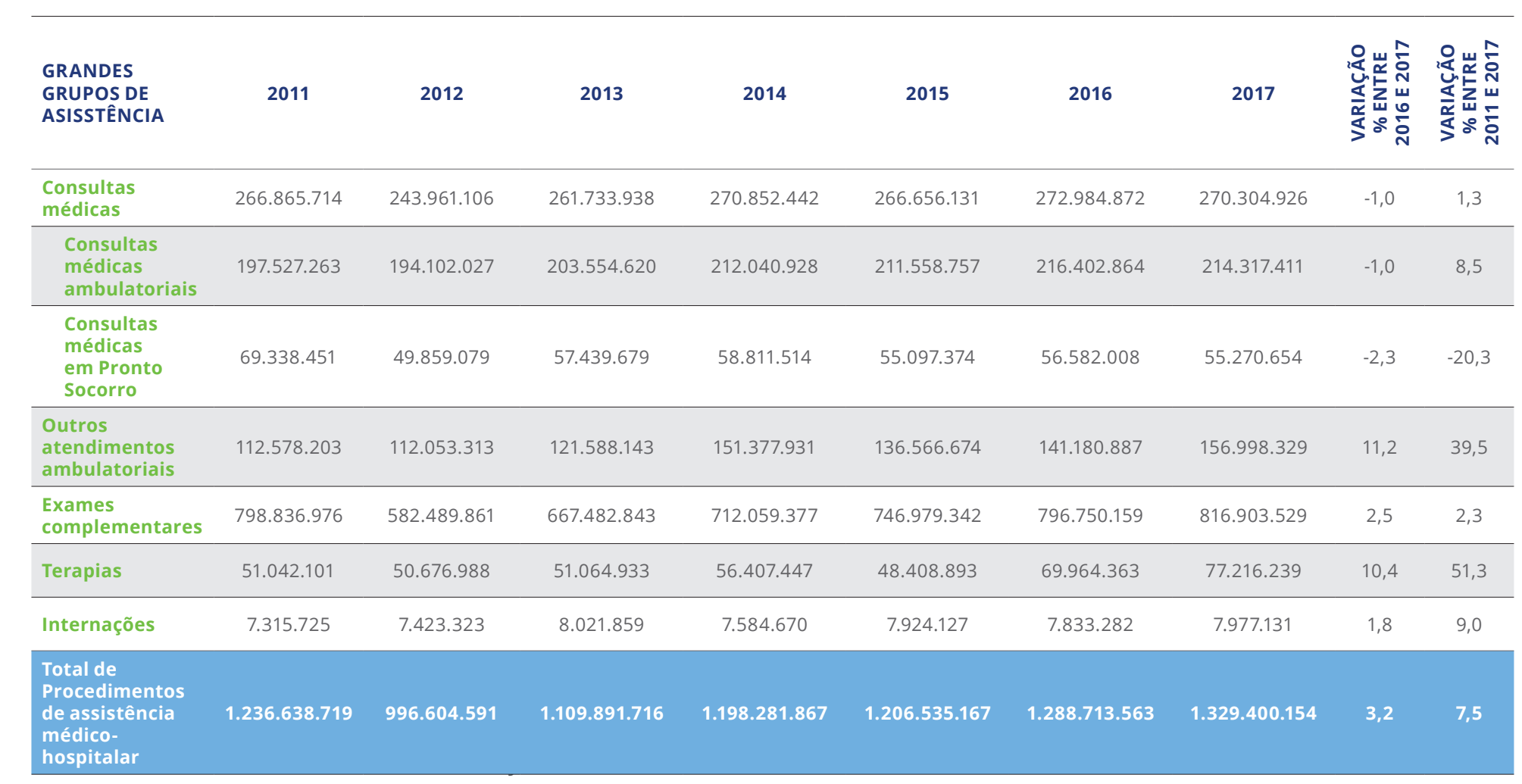

número de beneficiários de planos privados de assistência médico-hospitalar passou de 50,1 milhões em 2014 (maior valor desde o ano de 2000) para em 2017 (redução de 5,8\%). No entanto, essa queda não ocorreu fualmente para todas as faixas etárias. O número de vínculos entre os benemero de beneficiários entre 0 a 18 anos e de 19 a 58 anos esteve caindo desde 2014 (gráfico 1).

Gráfico 1. Evolução do número de beneficiários de planos médico-hospitalares (em milhões) por faixa etária e variação percentual em 36 meses. Brasil,
2000 a 2017 .
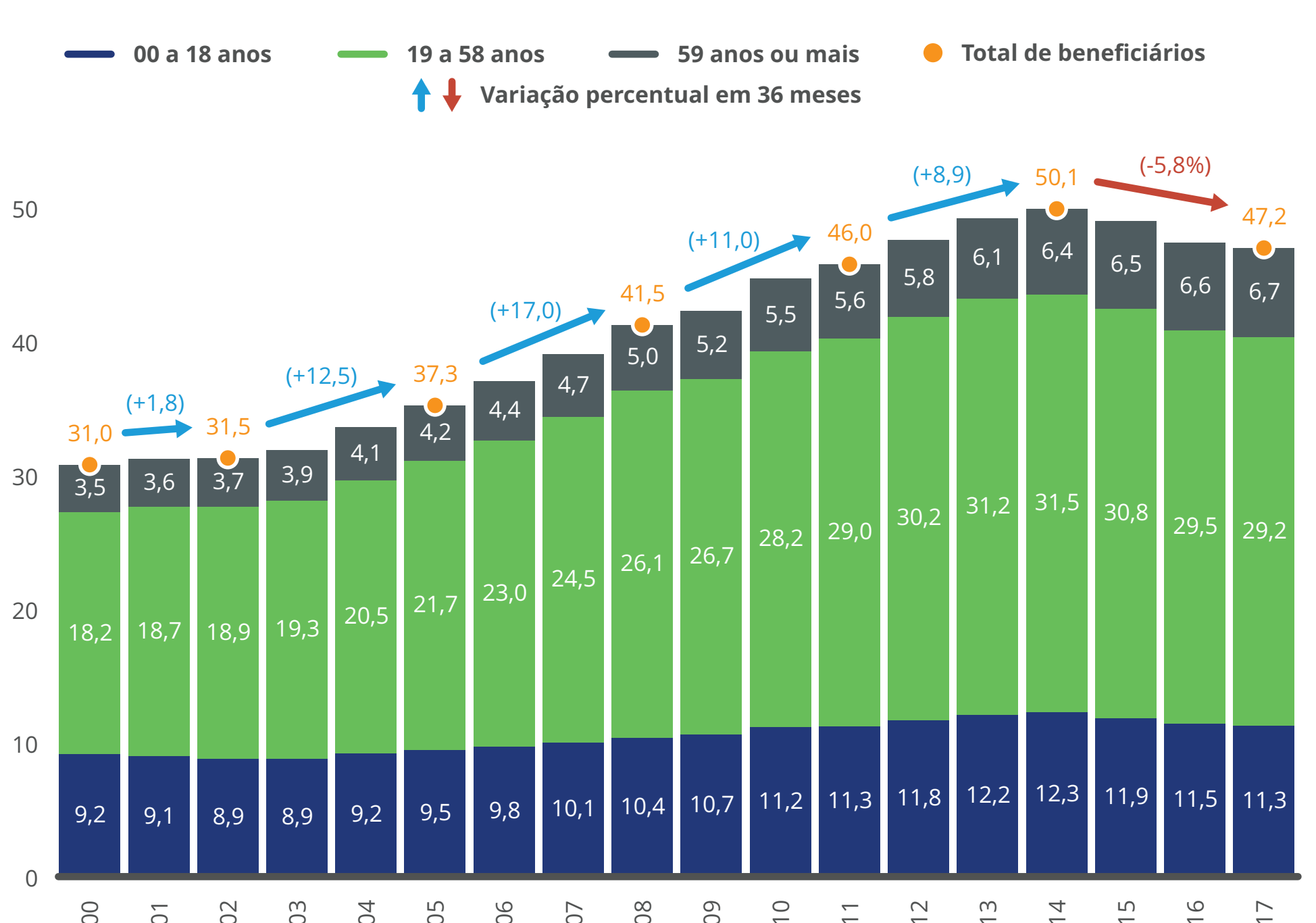

Observa-se que mesmo com as constantes quedas no número de beneficiários nos últimos três anos, a quantidade de procedimentos de assistência médicode consultas médicas, que foi a única a apresentar reducão $(-1,0 \%)$. Os demais procedimentos apresentaram aumento - consultas ou sessões com outros profissionais de saúde $(11,2 \%)$, terapias $(10,4 \%)$, exames complementares $(2,5 \%)$ e internação $(1,8 \%)$

Nesse mesmo período, com exceção das consultas, verifica-se na tabela 2 que houve aumento no numero médio de procedimentos por beneficiário de todos

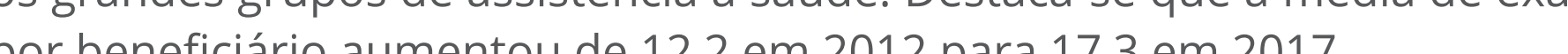
m 2017. onúmero médio de consultas ambulatoriais por ben

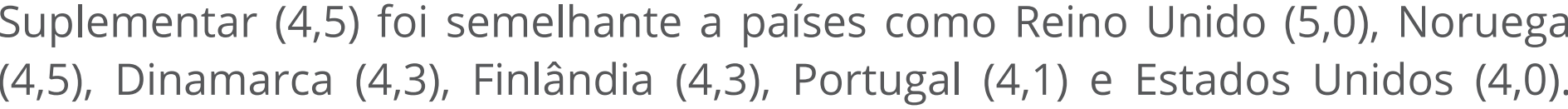
Ao olhar para o sistema público de saúde brasileiro como um todo, ou seja, para o Sistema Unico de Saúde (SUS), essa média foi de 2,8 consultas/habitante por exemplo (OCDE, 2017 e MS, 2018).

Tabela 2. Evolução do número médio de procedimentos de assistência médico-hospitalar por beneficiário prestados no sistema de saúde suplementar entre 2011 a 2017

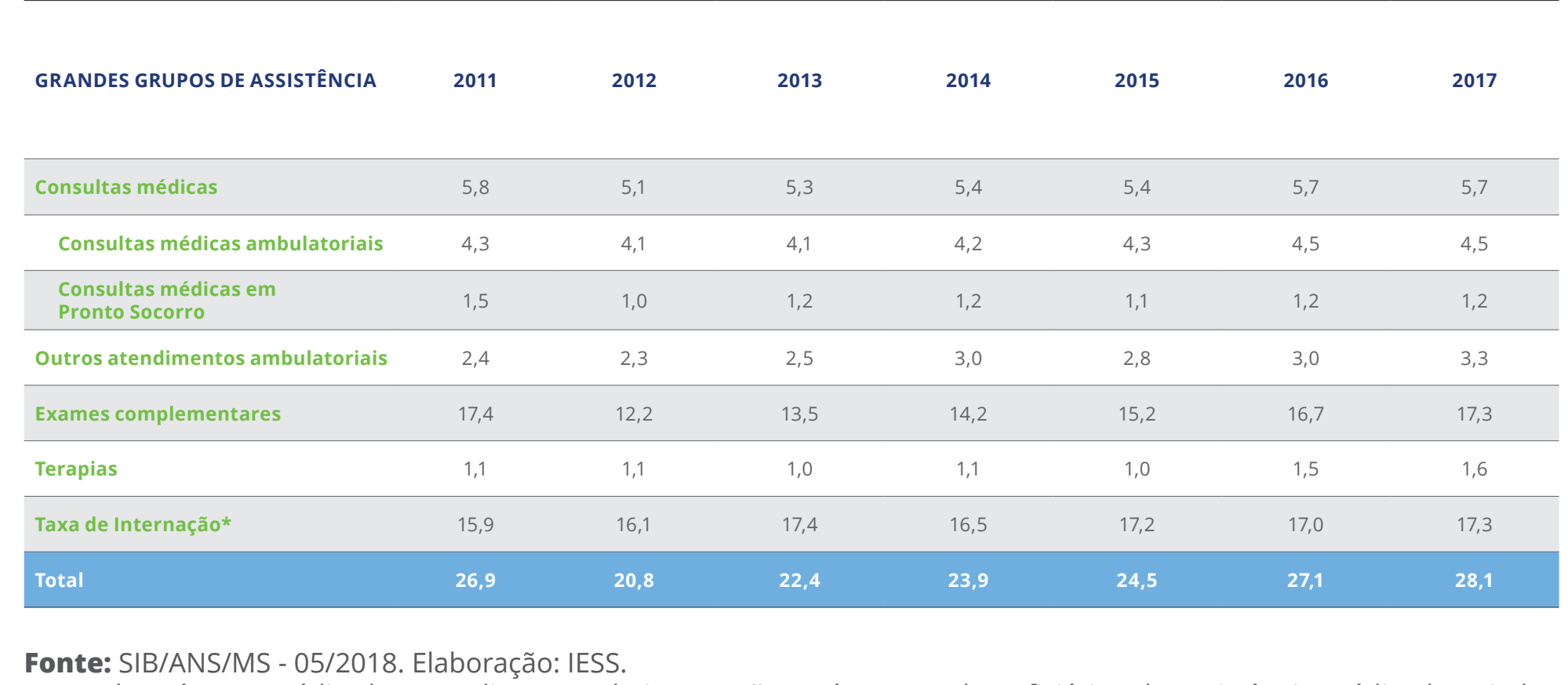

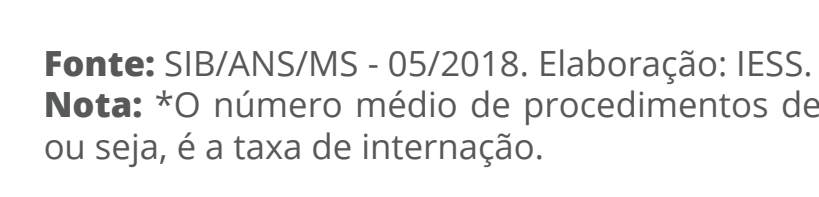

Em 2017, os planos médico-hospitalares gastaram R $\$ 144,9$ bihões (valores nominais) com serviços de assistência à saúde, valor 9,8\% maior em relação ao ano anterior. De 2011 a 2017 , o maior crescimento ocorreu nas terapias, no qual o gasto mais que triplicou (saltou de $R \$ 3,1$ bilhões para $R \$ 10,4$ bilihões crescimento de 229,9\%), seguido das consultas em pronto-socorro, consultas/ res e das internações, cujo gastos mais que dobraram (tabela 3).

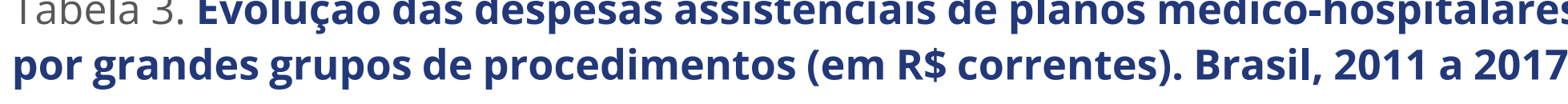
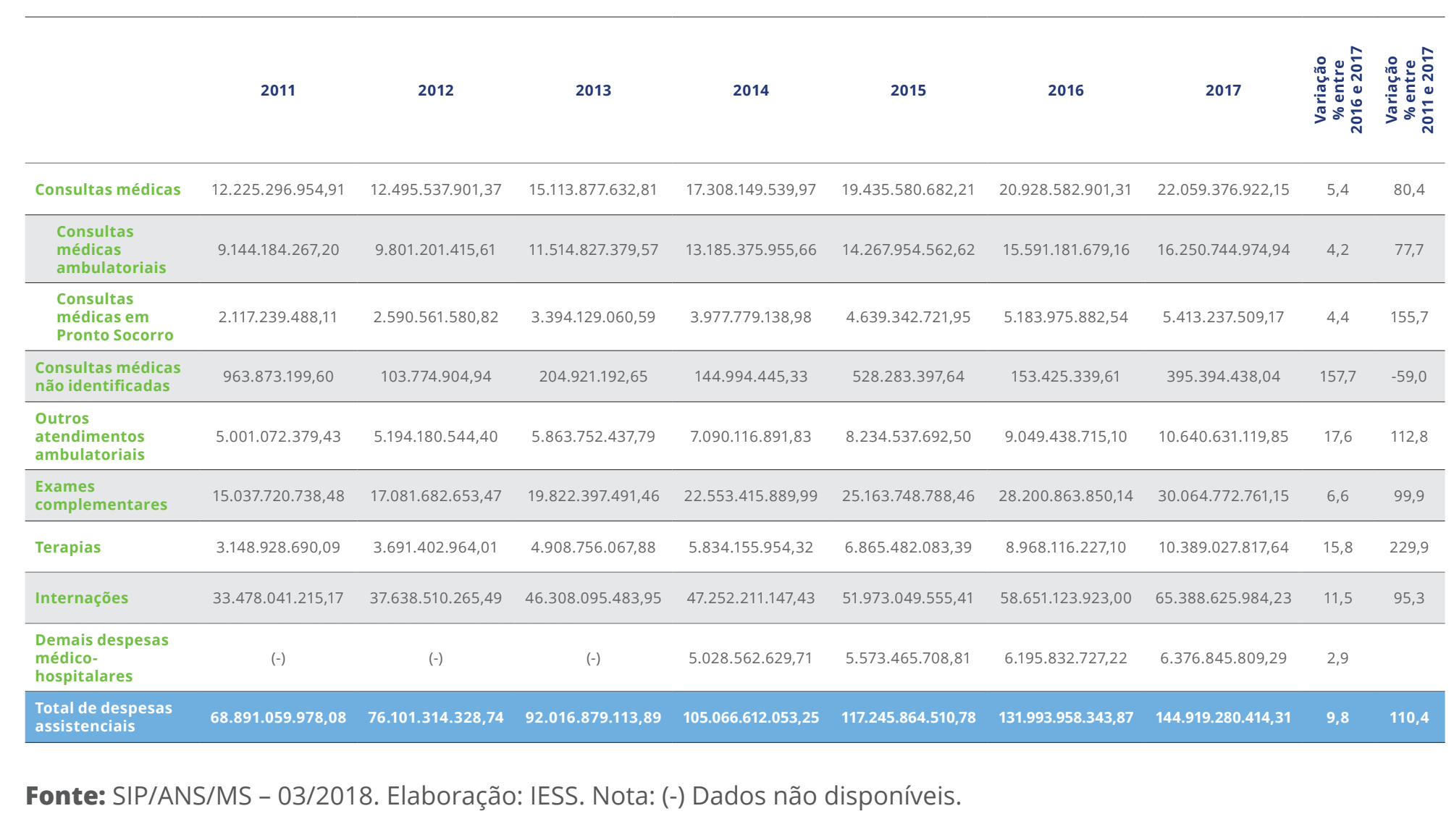

Ao observar o infografico 1, embora as internaçóes representem uma parcela pequena da quantidade de procedimentos assistenciais $(0,6 \%)$, elas represen-
Infográfico 1. Proporção de procedimentos e despesas assistenciais dos pla-
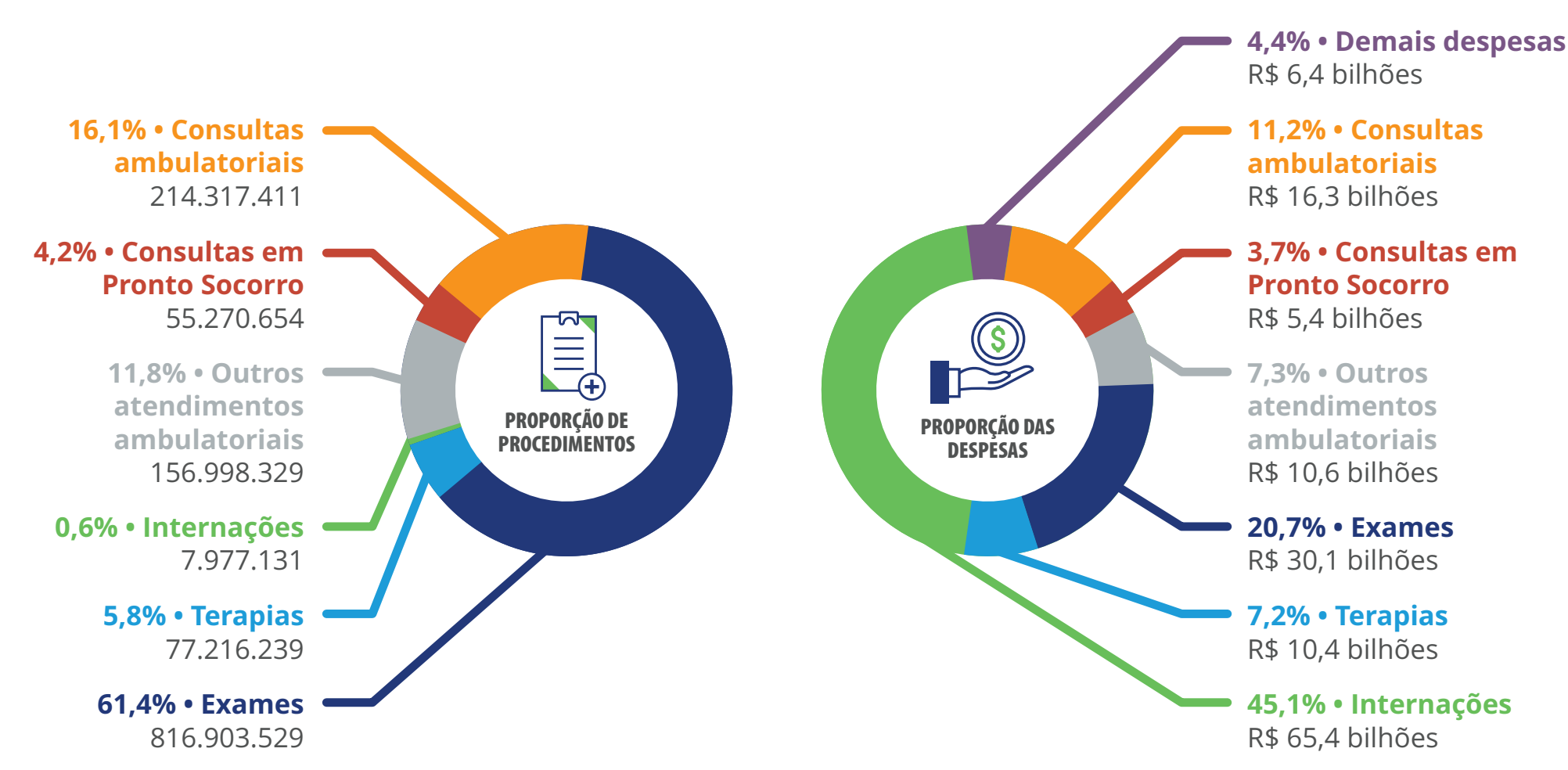

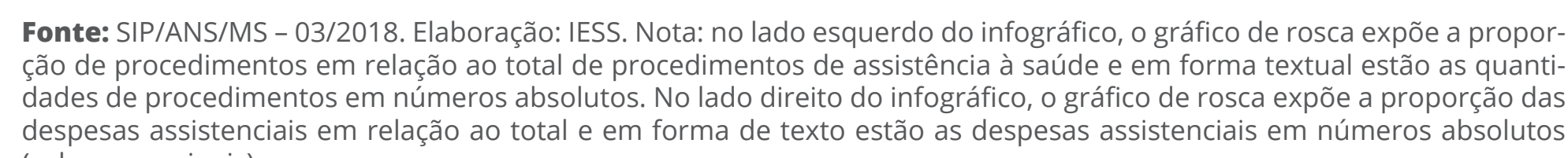

$>$ CONCLUSÕES

A redução do número de empregos formais nos últimos três anos convergiu n redução do número de beneficiaríios de planos de saúde médico-hospitalares. pesas assistenciais realizados na saúde suplementar. Espera-se que seus resultados suscitem discussões quanto a necessidade do avanço de açōes de prevenção de doenças e promoção da saúde e que aux liem a se pensar náo só as especificidades das populaçoes e suas caracteristicas epideniologicas, como também garantir, de forma estratégica, o eficiente em prol da qualidade assistencial.

$>$ NOTA TÉCNICA

- Osip náo e um sistema auditado e os dados sáo enviados periodicami las operadoras de planos privados de assistência à saúde à ANS

"um be eficiário pode possuir mais de um plano e assim cansar no sabnet: tantas vezes quantos forem os vínculos que possuir com planos privados de assistência à saúde"

Os dados estão sujeitos a revisão pela Agência Nacional de Saúde Suplementar (ANS) ou qualquer outra fonte citada;

Comparar os resultados da saúde suplementar com os países da Organização para a Cooperaçáa e Desenvolvimento Econômico (OCDE) por exemplo, que trativas, pois não éideal comparar um país com um grupo de pessoas (no caso. os beneficiários de planos de saúde.

> REFERÊNCIAS

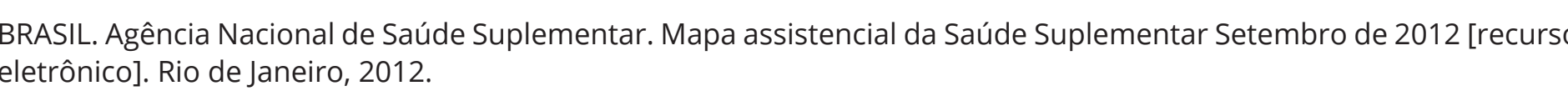

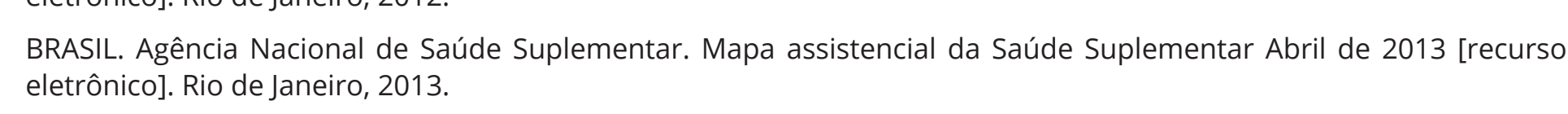

BRASLl. Agência Nacional de Sä

BRASLl. Agência Naç
Rio de janirio, 2016.

BRASLl. Agência Na
Rio de janeiro, 2017.

BRASLl. Agência Naca
Rio de Janeiro, 2018 .

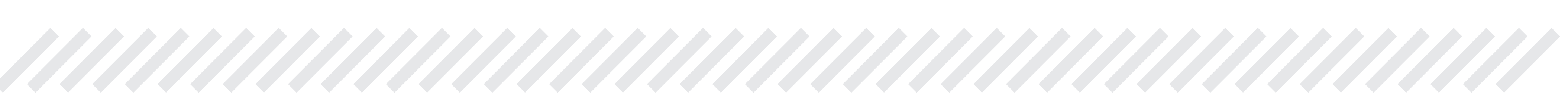

\section{www.iess.org.br}

(11) 3706-9747 - contato@iess.org.br
Rua Joaquim Floriano, 1052 - Conj. 42 Itaim Bibi - Paulo/SP - 04534-004 